\title{
Chest radiographic abnormalities in HIV-infected African children: a longitudinal study
}

\author{
Richard D Pitcher ${ }^{1}$ Carl J Lombard, ${ }^{2}$ Mark F Cotton, ${ }^{3}$ Stephen J Beningfield, ${ }^{4}$ \\ Lesley Workman, ${ }^{5}$ Heather J Zar ${ }^{5}$
}

\begin{abstract}
- Additional material is published online only. To view please visit the journal online (http://dx.doi.org/10.1136/ thoraxjn-2014-206105)
\end{abstract}

${ }^{1}$ Division of Radiodiagnosis, Department of Medical Imaging and Clinical Oncology, Tygerberg Hospital, Stellenbosch University, Cape Town, South Africa

${ }^{2}$ Biostatistics Unit, Medical Research Council, Cape Town, South Africa

${ }^{3}$ Department of Paediatrics and Child Health, Tygerberg Children's Hospital and Stellenbosch University, Cape Town, South Africa

${ }^{4}$ Division of Radiology, Department of Radiation Medicine, New Groote Schuur Hospital and University of Cape Town, Cape Town, South Africa

${ }^{5}$ Department of Paediatrics and Child Health, Red Cross War Memorial Children's Hospital and MRC Unit on Child \& Adolescent Health, University of Cape Town, Cape Town, South Africa

\section{Correspondence to} Professor Richard D Pitcher, Division of Radiodiagnosis, Department of Medical Imaging and Clinical Oncology, Tygerberg Hospital and Stellenbosch University, Francie van Zijl Avenue, Tygerberg, Cape Town 7505, South Africa;

pitcher@sun.ac.za

Received 29 July 2014 Revised 13 May 2015 Accepted 15 May 2015 Published Online First 9 June 2015

\section{ABSTRACT \\ Background There is limited knowledge of chest radiographic abnormalities over time in HIV-infected children in resource-limited settings.}

Objective To investigate the natural history of chest radiographic abnormalities in HIV-infected African children, and the impact of antiretroviral therapy (ART). Methods Prospective longitudinal study of the association of chest radiographic findings with clinical and immunological parameters. Chest radiographs were performed at enrolment, 6-monthly, when initiating ART and if indicated clinically. Radiographic abnormalities were classified as normal, mild or moderate severity and considered persistent if present for 6 consecutive months or longer. An ordinal multiple logistic regression model assessed the association of enrolment and timedependent variables with temporal radiographic findings. Results 258 children (median (IQR) age: 28 (13-51) months; median CD4+\%: 21 (15-24)) were followed for a median of 24 (18-42) months. $70(27 \%)$ were on ART at enrolment; 130 (50\%) (median age: 33 (18-56) months) commenced ART during the study. $154(60 \%)$ had persistent severe radiographic abnormalities, with median duration 18 (6-24) months. Among children on ART, $69 \%$ of radiographic changes across all 6 -month transition periods were improvements, compared with $45 \%$ in those not on ART. Radiographic severity was associated with previous radiographic severity (OR=120.80; $95 \% \mathrm{Cl} 68.71$ to 212.38), lack of ART $(\mathrm{OR}=1.72 ; 95 \% \mathrm{Cl} 1.29$ to 2.27$)$, enrolment age $<18$ months (OR=1.39; $95 \% \mathrm{Cl} 1.06$ to 1.83 ), diffuse, severe radiographic abnormality at enrolment $(\mathrm{OR}=2.18$; $95 \% \mathrm{Cl} 1.33$ to 3.56), hospitalisation for lower respiratory tract infection during the previous 6 months $(\mathrm{OR}=1.88 ; 95 \% \mathrm{Cl} 1.06$ to 3.30 ) and length of followup: at $18-24$ months $(\mathrm{OR}=0.66 ; 95 \% \mathrm{Cl} 0.49$ to 0.90$)$, and at $30-54$ months ( $O R=0.42 ; 95 \% \mathrm{Cl} 0.32$ to 0.56 ). Conclusions Most children had severe radiographic abnormalities persisting for at least 18 months. ART was beneficial, reducing the risk of radiographic deterioration or increasing the likelihood of radiological improvement.

\section{INTRODUCTION}

CrossMark

\section{To cite: Pitcher RD,} Lombard CJ, Cotton MF, et al. Thorax 2015;70: 840-846.
Acute and chronic respiratory illness is the leading cause of morbidity and mortality in HIV-infected children. ${ }^{1-4}$ This high burden of respiratory disease is reflected in abnormalities of the chest radiograph, a common investigation for respiratory illness. Although combination antiretroviral therapy (ART) programmes reduce incidence and severity of

\section{Key messages}

What is the key question?

- What is the cumulative prevalence of chest radiographic abnormalities in HIV-infected African children where antiretroviral therapy (ART) access was initially limited?

What is the bottom line?

- There is a very high $(60 \%)$ cumulative prevalence of persistent, severe chest radiographic abnormalities in HIV-infected African children, which can be reduced with subsequent ART.

\section{Why read on?}

- The main causes of persistent, severe chest radiographic abnormality will be identified and the benefits of subsequent ART quantified.

respiratory disease in HIV-infected children, there are limited longitudinal data on the chest radiographic abnormalities in HIV-infected children in low-income or middle-income countries (LMICs), especially where access to ART has been suboptimal. ${ }^{5-11}$

We have previously reported that among a group of HIV-infected South African children with late access to ART, over $50 \%$ demonstrated severe chest radiographic abnormalities, either confluent opacification, a nodular pattern or in combination. These radiographic patterns were most common in children aged 24-48 months and were associated with advanced HIV disease and immune suppression. ${ }^{12}$

Prior to the availability of ART comprising three antiretrovirals (ARV), a 4-year longitudinal study of 287 HIV-infected North American children, some of whom were receiving one or two ARVs, reported a $29 \%(n=83)$ cumulative prevalence of persistent chest radiographic abnormalities, with $23 \%(n=64)$ having severe abnormalities, manifesting as persistent consolidation or nodules. ${ }^{13}$ There is no comparable study in LMICs where a high burden of paediatric HIV disease, limited access to healthcare, malnutrition, poverty and a high incidence of respiratory infections such as pulmonary TB (PTB) contribute to respiratory morbidity. ${ }^{14}$

The aim of this study was to longitudinally investigate the prevalence, features and progression of chest radiographic abnormalities, and the impact of ART, in HIV-infected African children. 


\section{METHODS}

\section{Study population}

We conducted a prospective longitudinal study of HIV-infected children enrolled in an isoniazid (INH) prophylaxis trial at the Red Cross War Memorial Children's Hospital and Tygerberg Children's Hospital in Cape Town, South Africa. ${ }^{15} 16$ Children were recruited over a 5-year period, from December 2002 to November 2007. All children attended public healthcare facilities and were vertically infected.

\section{Clinical assessment}

Baseline

At enrolment, study investigators recorded a standardised baseline assessment on a customised case report form. This included a detailed history incorporating socioeconomic parameters, and a physical examination. CD4 count and percentage were measured. HIV-staging was according to the Centres for Disease Control and Prevention (CDC) clinical and immunological categories. ${ }^{17}$ For clinical suspicion of PTB, children had at least two induced sputa for smear and liquid culture. ${ }^{15} 16$

\section{Follow-up}

Patients were seen at monthly intervals for the first 6 months, 6-weekly for the next 6 months and 3-monthly thereafter. At each visit, an abbreviated history and physical examination, including height and weight, were undertaken. CD4+ cells and percentage were measured 12-monthly. Tuberculin skin testing was repeated 6-monthly if prior tests were negative.

Caregivers kept diaries of intercurrent illnesses and clinic attendance between study visits and a questionnaire reflecting diary entries was completed at each study visit. When a child was hospitalised, caregivers contacted a study investigator, thereby facilitating recording of hospitalisation data. Children hospitalised for acute lower respiratory tract infection (LRTI) were investigated for bacterial, viral, mycobacterial and fungal pathogens and treated according to current South African public sector guidelines. All hospitalisations for LRTIs were included on the study database.

Access to ART through public programmes became available from 2004. Follow-up for children commencing ART was according to standard guidelines for ART safety and compliance. ART adherence was assessed at each visit as percentage compliance, based on medication dispensed and returned.

Throughout the study, nutritional supplements (multivitamin syrup, elemental iron and folic acid) were prescribed as standard of care. In addition, Primary Health Care facilities provided food supplementation to moderately malnourished children. Severely malnourished children were hospitalised for initial management.

\section{Radiological assessment}

Anteroposterior and lateral chest radiographs were acquired at enrolment and then 6-monthly. Additional radiographs were performed prior to initiating ART or if hospitalised for LRTI, if PTB was suspected, or at the discretion of the treating doctor.

\section{Reporting}

A paediatric radiologist blinded to the clinical details undertook chest radiographic interpretation. The standardised reporting methodology and customised force-choice reporting template have been previously described (see online supplementary file 1 , 12). Overall radiographic severity was assigned according to the most advanced radiographic abnormality and stratified as grade 0 (normal), grade 1 (mild/moderate abnormality_bronchial wall thickening and/or mild atelectasis) or grade 2 (severe abnormality-confluent opacification, a nodular/reticulonodular/reticular pattern, moderate/severe atelectasis, bronchiectasis, cysts or cavities).

The distribution of severe (grade 2) features was further analysed on the anteroposterior radiograph by dividing each lung into three zones. Focal disease was confined to one zone, multifocal to between two and four zones, and diffuse when in more than four zones.

\section{Statistical analysis}

Descriptive statistics (frequencies, medians, IQRs and proportions) were calculated at baseline and across time. To assess the differences between the subgroup without follow-up radiographs and the study cohort with follow-up radiographs, baseline demographic and clinical characteristics were compared using 2-sample $\mathrm{t}$ tests and $\chi^{2}$ tests.

The cumulative prevalence and median duration of persistent, severe radiographic abnormality was calculated by analysis of the longitudinal radiographic status of individual patients. Any child showing severe abnormality on consecutive 6-monthly follow-up radiographs was considered to have persistent severe abnormality. The number of consecutive radiographs demonstrating severe abnormality determined its duration. Descriptive tables of transition in the radiographic status of the cohort were compiled at each 6-monthly point of follow-up and stratified by ART status. As a summary descriptive metric, the cumulative total of transitions (improvement and deterioration) was calculated for ART and non-ART periods.

To assess radiographic severity over time, an ordinal multiple logistic regression model included independent variables from two components of the study, (A) enrolment variables (gender, age in months, anthropometric data, CDC clinical classification, CD4+\%, radiographic severity, active PTB, hospitalisation for LRTI, INH prophylaxis, ART status) and (B) time dependent variables (radiographic severity 6 months prior, hospitalisation for LRTI within the preceding 6 months, diagnosis of active PTB in the preceding 6 months, INH status at the preceding 6-monthly clinical evaluation, ART status, CD4+\% and anthropometric data at each point of follow-up). Using radiographic findings in the preceding 6 months as a variable in the model made this a transitional model for radiographic severity.

In addition, changes in the composition and chest radiographic severity risk of the cohort due to withdrawals, death or duration of follow-up were accommodated by incorporating a time factor termed 'length of follow-up'. This key model component was defined by the three time periods, 6-12 months, 18-24 months and 30-54 months, and was used to evaluate the differential effects over time of risk factors such as anthropometric data, CD4+\%, use of ART, INH treatment status and prior radiographic severity. The evaluation was performed by incorporating various interaction terms into the model and testing them for significance; none were significant.

The model accounted for the dependency of repeated measures for each participant by using a robust cluster variance approach. Multiple imputations $(n=20)$ of missing covariate values for ART (1\% missing), CD4+\% (13\% missing) and the weight-for-age z-score (WHOWAZ, 24\% missing) were done for the model. For the imputations, logistic and multivariate normal regression models were used with complete baseline covariates such as age, sex, INH status and radiological class.

To evaluate the proportional odds assumption as the outcome in the ordinal multiple logistic regression model, an approximate likelihood ratio test was applied across the radiographic 


\section{Paediatric lung disease}

severity categories as follows: grade 0 versus grade $1 / 2$ and grade $0 / 1$ versus grade 2 .

\section{RESULTS}

\section{Study population}

Of 330 children enrolled, 24 (7\%) died and 24 (7\%) were withdrawn in the first 6 months, while $24(7 \%)$ did not have retrievable follow-up radiographs. The remaining 258 children $(78 \% ; \mathrm{m}=138$, 53\%; median (IQR) age: 28 (13-51) months) had at least one follow-up radiograph and were included in this analysis, contributing 2024 radiographic studies. During follow-up 8 children (3\%) died, while 74 (29\%) were withdrawn from the study (table 1).
Comparison between the subgroup with no radiographic follow-up $(n=72)$ and the study cohort $(n=258)$ showed no significant difference in radiographic profile at enrolment. However, those without follow-up radiographs were younger, malnourished and had more advanced HIV disease.

\section{Socioeconomic features}

All 258 children were from poor urban or peri-urban backgrounds. Almost half $(120,47 \%)$ lived in informal housing, more than half $(141,55 \%)$ were without running water in their homes, while $146(57 \%)$ used outside toilet facilities.

Table 1 Study population

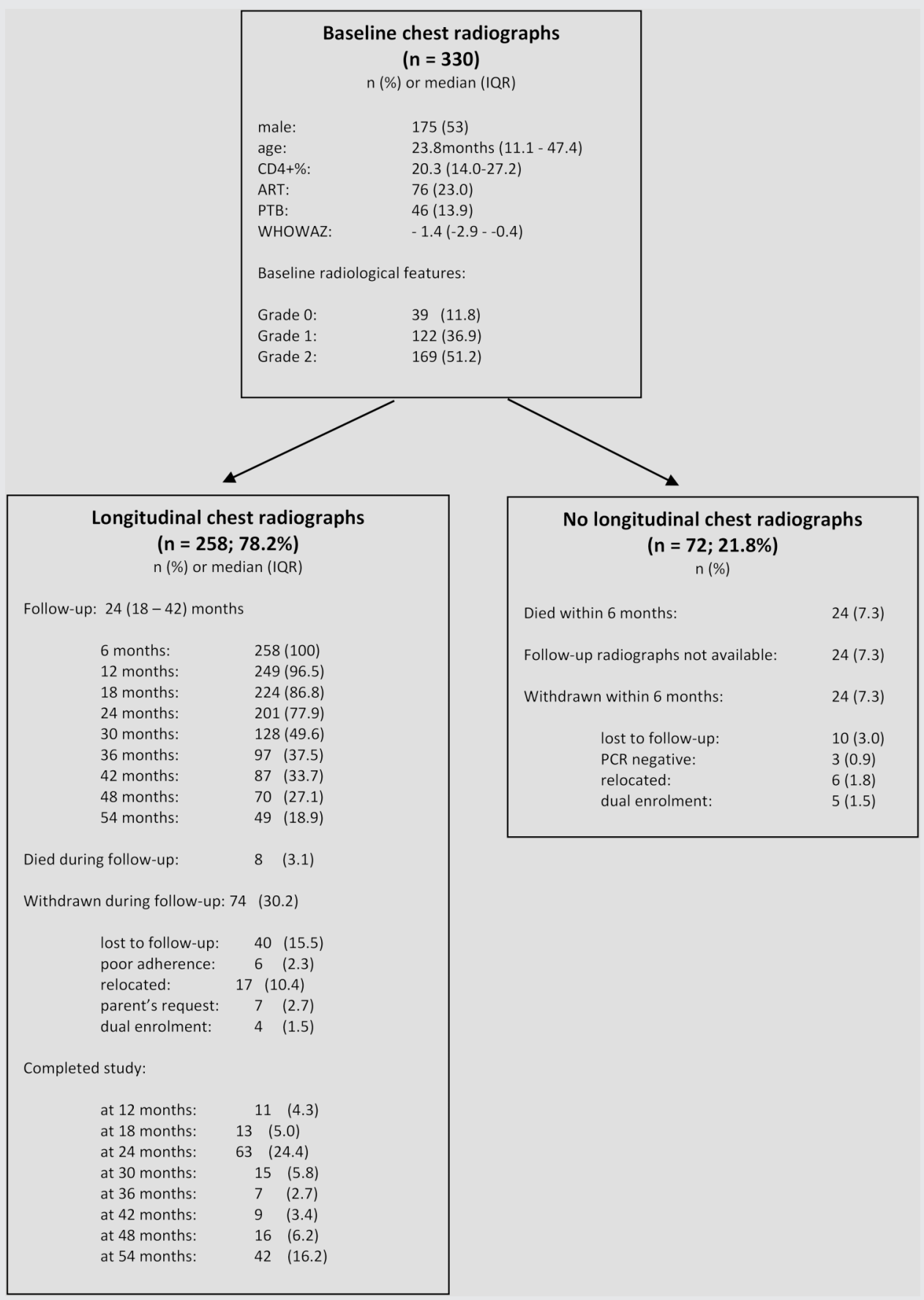


Table 2 Demographic and clinical findings over time

\begin{tabular}{|c|c|c|c|c|c|c|c|c|c|c|}
\hline $\begin{array}{l}\text { Parameter } \\
\text { n (\%), median (IQR) }\end{array}$ & $\begin{array}{l}\text { Baseline } \\
\mathrm{n}(\%)\end{array}$ & $\begin{array}{l}6 \text { months } \\
\mathrm{n}(\%)\end{array}$ & $\begin{array}{l}12 \text { months } \\
\mathrm{n}(\%)\end{array}$ & $\begin{array}{l}18 \text { months } \\
\text { n (\%) }\end{array}$ & $\begin{array}{l}24 \text { months } \\
\text { n }(\%)\end{array}$ & $\begin{array}{l}30 \text { months } \\
\mathrm{n}(\%)\end{array}$ & $\begin{array}{l}36 \text { months } \\
\mathrm{n}(\%)\end{array}$ & $\begin{array}{l}42 \text { months } \\
\mathrm{n}(\%)\end{array}$ & $\begin{array}{l}48 \text { months } \\
\mathrm{n}(\%)\end{array}$ & $\begin{array}{l}54 \text { months } \\
\text { n (\%) }\end{array}$ \\
\hline Total & $258(100)$ & $258(100)$ & $249(97)$ & $224(87)$ & $201(78)$ & $128(50)$ & $97(38)$ & $86(33)$ & $70(27)$ & 49 (19) \\
\hline Male & $138(53)$ & $138(53)$ & $131(53)$ & $118(53)$ & $109(54)$ & $63(49)$ & $48(49)$ & $42(49)$ & $35(50)$ & $22(45)$ \\
\hline Age in months & $28(13-51)$ & $33(19-56)$ & $39(25-62)$ & $45(30-70)$ & $50(34-75)$ & $52(40-73)$ & $60(47-76)$ & $64(52-83)$ & 70 (59-89) & 79 (65-96) \\
\hline On ART & $70(27)$ & $115(45)$ & $159(64)$ & $163(73)$ & $157(78)$ & $101(82)$ & $80(82)$ & $71(83)$ & $58(83)$ & $38(78)$ \\
\hline CD4+\% & $21(15-28)$ & $21(15-29)$ & $24(18-30)$ & $25(18-31)$ & $27(20-33)$ & $26(20-32)$ & $27(21-34)$ & $29(23-35)$ & $30(25-37)$ & $32(25-35)$ \\
\hline Weight-for-age $z$-score $<2$ & $84(33)$ & $73(28)$ & $62(25)$ & $43(19)$ & $33(16)$ & $18(14)$ & $15(15)$ & $14(16)$ & $11(16)$ & $9(18)$ \\
\hline PTB diagnosed in period & $37(14)$ & $16(6)$ & $11(4)$ & $5(2)$ & 0 & $2(1)$ & $1(0)$ & $1(0)$ & 0 & 0 \\
\hline Hospitalised in period & $\mathrm{n} / \mathrm{a}$ & 48 (19) & $34(13)$ & $11(4)$ & $9(3)$ & $3(1)$ & $5(2)$ & $1(0)$ & 0 & 0 \\
\hline \multicolumn{11}{|l|}{ CDC clinical category } \\
\hline $\mathrm{N}$ & $3(1)$ & $2(1)$ & $2(1)$ & $0(0)$ & 0 & 0 & 0 & 0 & 0 & 0 \\
\hline A & $22(9)$ & $12(5)$ & $10(4)$ & $4(2)$ & 2 & 0 & 0 & 0 & 0 & 0 \\
\hline B & $163(63)$ & $158(61)$ & $145(58)$ & $127(57)$ & $109(54)$ & $56(44)$ & $45(46)$ & $36(42)$ & $26(37)$ & $16(33)$ \\
\hline$C$ & $70(27)$ & $86(33)$ & 92 (37) & $93(42)$ & 90 & $72(56)$ & $52(54)$ & $50(58)$ & $44(63)$ & $33(67)$ \\
\hline
\end{tabular}

\section{Clinical features}

At enrolment, 233 (90\%) had moderate or advanced clinical HIV disease and most had moderate immune suppression (median (IQR) CD4+\%=21 (15-28)) (table 2). Thirty-seven $(14 \%)$ had PTB at enrolment, 3 being culture-confirmed and 34 clinically diagnosed. Seventy children $(27 \%)$ were already on ART at enrolment, for a median of 7 (5-15) months (table 2). During the study, an additional 130 children (50\%), median age 33 (18-56) months, commenced ART. At study end, 200 (78\%) were on ART, having received treatment for a median of 16 (925) months.

Median length of follow-up was 24 (18-42) months, during which 72 children $(28 \%)$ required at least one hospitalisation for acute LRTI, with 39 (15\%) having multiple admissions. Sixty-one patients $(24 \%)$ had disease progression by CDC clinical category. On final analysis, 250 (97\%) had moderate or advanced clinical HIV disease. An additional 36 children (14\%) developed PTB during the study, of whom, 14 were cultureconfirmed and 22 diagnosed on clinical criteria. The immunological status of children followed for 54 months (median CD4 $+\%=32(26-36))$ showed sustained improvement from enrolment (median CD4+\%=21 (15-28)).

At enrolment, a third of the cohort $(n=84,33 \%)$ had a WHOWAZ below -2 . For the first 2 years of follow-up there was steady improvement in nutritional status. By 24 months, the
WHOWAZ was below -2 in only 33 subjects (17\%). Thereafter, there was little further nutritional improvement. Persistent failure to thrive was ascribed to late diagnosis of HIV infection and delayed access to ART.

\section{Radiological progression}

At enrolment, 229 (89\%) children had a chest radiographic abnormality, with 130 (50\%) showing severe (grade 2) abnormality (table 3 , see online supplementary file 2 ). In the first 6 months, the proportion with severe abnormality increased slightly from $50 \%$ to $53 \%$, remaining unchanged at 12 months. Subsequently, slow but sustained radiological improvement was noted, with $40 \%, 28 \%, 19 \%$ and $16 \%$ showing severe abnormality at 24 months, 36 months, 48 months and 54 months, respectively. The cumulative incidence of persistent, severe abnormality was 154 (60\%), with a median duration of 18 (1224) months.

Nodules alone $(n=49)$, or with homogeneous opacification $(n=73)$, accounted for $122(79 \%)$ cases of persistent, severe abnormality, visualised for a median of 18 (12-24) months. Nodule distribution was predominantly symmetrical and either multifocal or diffuse $(n=107 ; 97 \%)$, with a mean nodule diameter of $2 \mathrm{~mm}$.

Seventy-one patients (28\%) with persistent nodules met CDC criteria for lymphocytic interstitial pneumonitis (LIP). ${ }^{18}$ Of

Table 3 Radiological findings over time

\begin{tabular}{|c|c|c|c|c|c|c|c|c|c|c|}
\hline Radiological parameters & $\begin{array}{l}\text { Baseline } \\
\text { n (\%) }\end{array}$ & $\begin{array}{l}6 \text { months } \\
\mathrm{n}(\%)\end{array}$ & $\begin{array}{l}12 \text { months } \\
\mathrm{n}(\%)\end{array}$ & $\begin{array}{l}18 \text { months } \\
\text { n (\%) }\end{array}$ & $\begin{array}{l}24 \text { months } \\
n(\%)\end{array}$ & $\begin{array}{l}30 \text { months } \\
\mathrm{n}(\%)\end{array}$ & $\begin{array}{l}36 \text { months } \\
\text { n (\%) }\end{array}$ & $\begin{array}{l}42 \text { months } \\
\text { n (\%) }\end{array}$ & $\begin{array}{l}48 \text { months } \\
\text { n (\%) }\end{array}$ & $\begin{array}{l}54 \text { months } \\
\mathrm{n}(\%)\end{array}$ \\
\hline Same & - & $182(70)$ & $186(75)$ & $166(74)$ & $155(77)$ & $94(74)$ & $71(73)$ & $63(73)$ & $52(74)$ & $37(78)$ \\
\hline Improved & - & $28(11)$ & $40(16)$ & $46(21)$ & $22(11)$ & $27(21)$ & $18(19)$ & $17(20)$ & $10(14)$ & $8(14)$ \\
\hline Deteriorated & - & $48(19)$ & $23(9)$ & $12(5)$ & $24(12)$ & $6(5)$ & $8(8)$ & $6(7)$ & $8(11)$ & $4(8)$ \\
\hline Grade 0 & $28(11)$ & $13(5)$ & $33(13)$ & $37(17)$ & $34(17)$ & $35(27)$ & $28(29)$ & $35(41)$ & $29(41)$ & $23(43)$ \\
\hline Grade 1 & $100(39)$ & $107(41)$ & $83(33)$ & $95(42)$ & $86(43)$ & $45(35)$ & $42(43)$ & $33(38)$ & $28(40)$ & $218(41)$ \\
\hline Grade 2 & $130(50)$ & $138(54)$ & $133(54)$ & $92(41)$ & $81(40)$ & $47(37)$ & $27(28)$ & $18(21)$ & $13(19)$ & $8(16)$ \\
\hline Nodules alone & $30(12)$ & $47(18)$ & $48(19)$ & $45(20)$ & $40(20)$ & $22(17)$ & $11(11)$ & $8(9)$ & $4(6)$ & $5(10)$ \\
\hline Opacification alone & $59(23)$ & $41(16)$ & $41(16)$ & $16(7)$ & $20(10)$ & $15(12)$ & $7(7)$ & $6(7)$ & $6(9)$ & $1(2)$ \\
\hline Nodules with opacification & $41(16)$ & $50(19)$ & $44(18)$ & $29(13)$ & $20(10)$ & $13(10)$ & $5(5)$ & $1(1)$ & $2(3)$ & $0(0)$ \\
\hline Bronchiectasis & $7(3)$ & $13(5)$ & $17(7)$ & $14(6)$ & $22(11)$ & $13(10)$ & $9(9)$ & 7 (8) & $7(10)$ & $4(8)$ \\
\hline
\end{tabular}


these, $46(65 \%)$ had a purely nodular chest radiographic pattern, while $25(35 \%)$ had areas of superimposed persistent confluent opacification during follow-up. Thirty-six patients (median CD4+\%=18 (14-30); median age: 43 (31-69) months) had LIP at enrolment and 35 (median CD4+\%=20 (16-27); median age: 35 (23-54) months) developed LIP during the study.

Persistent homogeneous opacification occurred in 32 cases (21\%) and was present for a median of 12 (6-18) months.

Of the 73 children diagnosed with PTB, 47 (64\%) had persistent severe abnormality, with a median duration of 24 (18-30) months. Homogeneous opacification alone or nodules with opacification were each noted in 19 cases (40\%), while nodules alone occurred in 9 cases (19\%). The median age at the time of PTB diagnosis was 31 (13-61) months and the median CD4+\% at diagnosis was 18 (13-25).

Repeated hospitalisation for acute LRTI was implicated in persistent severe radiographic abnormality in eight patients (3\%).

At enrolment, seven (3\%) patients (median age: 19 (17-38) months; median CD4+\%=21 (19-22)) had features of bronchiectasis. A further 24 (9\%) patients (median age: 27 (24-67) months; median CD4+\%=20 (13-28)) developed radiographic signs of bronchiectasis during the study. Twenty-nine of these 31 patients (94\%) also had persistent nodules and/or opacification. Thus, bronchiectasis alone accounted for less than $1 \%$ of the persistent severe radiographic abnormalities in our cohort, but in combination with other severe abnormalities was implicated in $12 \%$ of cases. Eleven patients with LIP $(15 \%)$ developed features of bronchiectasis at a median of $12(6-12)$ months after the onset of LIP and 10 patients with PTB (10/47; 21\%) developed such features at a median of $6(0-12)$ months after the PTB diagnosis. Bronchiectasis was basal in 28 cases $(90 \%)$ and multifocal in 25 (80\%). Tubular bronchiectasis $(n=25,81 \%)$ predominated with $6(19 \%)$ showing cystic features.

\section{Impact of ART}

There was good adherence to ART, with 190 children (95\%) reaching at least 90\% compliance (see online supplementary file 3). Among children on ART, 69\% (162/235) of changes in chest radiographic status across all the 6-month transition periods were improvements, and 31\% (73/235) were deteriorations. By comparison, among those not on ART, 45\% (54/120) of all changes were improvements and 55\% (66/120) deteriorations. Thus, compared with those not on ART, children on ART had 24\% more improvements and 24\% fewer deteriorations across the transition periods.

\section{Ordinal multiple logistic regression analysis}

A main-effects model is presented, since evaluation of the interaction of follow-up time with prior chest radiographic severity and ART status revealed that neither was significant $(p=0.1551$ and $\mathrm{p}=0.1219$, respectively) (table 4 ). The approximate likelihood ratio test of proportionality of odds across radiographic severity categories confirmed the assumption that the estimated regression coefficients were equal across categories $(p=0.1666)$.

Chest radiographic severity was associated with radiographic abnormality on the previous film, absence of ART, enrolment age less than 18 months, diffuse severe radiographic abnormality at enrolment, hospitalisation for acute respiratory tract infection in the preceding 6 months and the duration of follow-up (table 4).

The influence of prior chest radiographic severity was most striking when the previous radiograph demonstrated severe (grade 2) abnormality. Here, the odds for remaining in the severe abnormality class were 120 times greater than a child
Table 4 Ordinal multiple logistic regression analysis

\begin{tabular}{|c|c|c|}
\hline Risk factor & OR $(95 \% \mathrm{Cl})$ & $\mathrm{p}$ Value \\
\hline \multicolumn{3}{|l|}{ Age below 18 months at enrolment } \\
\hline No & 1.00 & \\
\hline Yes & 1.40 (1.06 to 1.83$)$ & 0.016 \\
\hline \multicolumn{3}{|l|}{$\begin{array}{l}\text { Diffuse, severe, radiological } \\
\text { abnormality at enrolment }\end{array}$} \\
\hline No & 1.00 & \\
\hline Yes & 2.18 (1.34 to 3.56$)$ & $<0.002$ \\
\hline Radiological severity 6 months prior & & $<0.001$ \\
\hline grade 0 & 1.00 & \\
\hline grade 1 & 10.71 (6.92 to 16.55$)$ & $<0.001$ \\
\hline grade 2 & 120.80 (68.71 to 212.38 ) & $<0.002$ \\
\hline \multicolumn{3}{|l|}{ Hospitalised in the last 6 months } \\
\hline No & 1.00 & \\
\hline Yes & 1.87 (1.07 to 3.30$)$ & 0.029 \\
\hline \multicolumn{3}{|l|}{ On ART } \\
\hline Yes & 1.00 & \\
\hline No & 1.72 (1.29 to 2.27$)$ & $<0.001$ \\
\hline Months on the study (months) & & $<0.0001$ \\
\hline $6-12$ & 1.00 & \\
\hline $18-24$ & $0.66(0.49$ to 0.90$)$ & 0.008 \\
\hline $30-54$ & 0.37 (0.28 to 0.51$)$ & $<0.001$ \\
\hline \multicolumn{3}{|l|}{ Diagnosed with TB } \\
\hline No & 1.00 & \\
\hline Yes & 2.87 (0.95 to 8.64$)$ & 0.060 \\
\hline \multicolumn{3}{|l|}{ Gender } \\
\hline Male & 1.00 & \\
\hline Female & $0.97(0.75$ to 1.25$)$ & 0.811 \\
\hline $\mathrm{CD} 4+\%$ & $0.99(0.90$ to 1.00$)$ & 0.062 \\
\hline CDC clinical classification & & 0.211 \\
\hline $\mathrm{A}+\mathrm{N}$ & 1.00 & \\
\hline B & 1.63 (0.78 to 3.38$)$ & 0.192 \\
\hline $\mathrm{C}$ & 1.91 (0.88 to 4.12 ) & 0.101 \\
\hline \multicolumn{3}{|l|}{ INH at visit 6 months prior } \\
\hline Yes & 1.0 & \\
\hline No & 1.39 (0.99 to 1.96$)$ & 0.056 \\
\hline Weight-for-age z-score & 98 (0.90 to 1.08$)$ & 0.747 \\
\hline
\end{tabular}

with a normal radiograph at the preceding visit $(\mathrm{OR}=120.80$; 95\% CI 68.71 to 212.38 ). Similarly, a mild (grade 1) abnormality on the previous film increased the probability of progression to severe abnormality on the subsequent film by 10 -fold $(\mathrm{OR}=10.70 ; 95 \%$ CI 6.93 to 16.55$)$.

For a child not on ART, the odds of having a more severe abnormality were almost double that of a child on ART $(\mathrm{OR}=1.72 ; 95 \% \mathrm{CI} 1.29$ to 2.27$)$ independent of the period of follow-up. At each point of follow-up, children younger than 18 months at enrolment had an almost 40\% increased risk of being in a higher severity category compared with children older than 18 months at enrolment $(\mathrm{OR}=1.39$; 95\% CI 1.06 to 1.83 ).

Diffuse, severe radiographic abnormality at enrolment had a detrimental effect over the whole study period, more than doubling the odds of increased radiological severity, compared with children without this feature $(\mathrm{OR}=2.18$; 95\% CI 1.33 to 3.56$)$.

Hospitalisation for LRTI in the preceding 6 months almost doubled the risk of being in a more severe category, compared with a child not hospitalised $(\mathrm{OR}=1.88 ; 95 \%$ CI 1.06 to 3.30$)$. 
The risk of being in a more severe category declined significantly with time. Compared with children followed for 612 months, those followed for 18-24 months had reduced risk of severe radiographic disease $(\mathrm{OR}=0.66,95 \%$ CI 0.49 to 0.90 ), while those followed for 30-54 months had a further reduction $(\mathrm{OR}=0.37,95 \% \mathrm{CI} 0.28$ to 0.51$)$. Gender, $\mathrm{CDC}$ clinical classification, PTB, anthropometric parameters, CD4+\% and INH usage were not associated with radiographic severity (table 4).

\section{DISCUSSION}

In this first longitudinal analysis of chest radiographic abnormalities in HIV-infected African children, we found a 60\% cumulative prevalence of persistent severe abnormality, almost threefold above HIV-infected North American children prior to the availability of ART. ${ }^{13}$ In the US study, persistent abnormality was defined as present for 3 consecutive months or longer, in contrast to our definition of 6 months or longer. The prevalence of persistent changes in our study therefore represents a conservative estimate. The high prevalence of persistent and severe radiographic abnormalities highlights the substantial burden of HIV-associated chronic respiratory disease in children in sub-Saharan Africa (SSA).

LIP (45\%) and PTB (31\%) were the leading causes of persistent, severe abnormality, accounting for over three quarters of cases. In the North American study, the cause of severe abnormality was established in 23 of 64 cases (35\%); LIP (16/64; $25 \%)$ predominated, followed by chronic Pneumocystis infection $(5 / 64 ; 8 \%)$ and PTB $(2 / 64,3 \%){ }^{13}$ The 10 -fold higher prevalence of PTB in our cohort underscores the significant PTB burden in SSA. ${ }^{19}$ The prevalence of LIP is also higher than reported by Norton $(16 / 287 ; 6 \%)$, but comparable to retrospective studies of symptomatic HIV-infected children in North America and the UK. ${ }^{20-23}$ Reasons for the variable incidence of LIP may relate to the epidemiology of Epstein-Barr virus (EBV) infection, which has been implicated in LIP pathogenesis, ${ }^{24-26}$ to the diagnostic criteria used, age range and selection of patient populations.

The preceding chest radiograph was the single most important predictor of subsequent radiological severity. This strong association reflects the intractability of the underlying lung disease, as exemplified by LIP and PTB, where severe abnormalities persisted for a median of 18 months and 24 months, respectively. This study therefore provides important new information on the persistence of severe radiological abnormality in HIV-associated pulmonary disease. The study also suggests that repeated chest radiographs are not indicated in HIV-infected children with severe radiological findings without clinical deterioration.

Importantly, we have shown that ART can decrease the risk of progression to severe radiographic abnormality and ameliorate established abnormality. The benefits of ART manifested within 6 months of commencing treatment and the beneficial effects were quantifiably sustained across all time periods. ART almost halved the burden of radiological severity at each time point, especially in LIP and PTB. The impact of ART on LIP has, to our knowledge, not been previously described in children. Thus far, a single study documented complete resolution of $\mathrm{LIP}^{27}$ in four of five adults (80\%) after 6 months of ART. Further study of the pathogenesis and immunological correlates of LIP are required to better understand the mechanism of radiological improvement. The ART-related radiographic response in PTB may be achieved through arresting clinical progression of HIV disease, ${ }^{28}{ }^{29}$ enhancing immunity ${ }^{30}$ or increasing the efficacy of TB treatment. ${ }^{11}$
The findings of this study suggest that early initiation of ART may prevent the radiological abnormalities documented in this cohort. We found that young age and diffuse, severe radiographic abnormality at enrolment (when a minority of children was on ART) were associated with radiographic severity at each point of follow-up, that ART had a sustained capacity to prevent and reverse radiological abnormality, and that there was a natural tendency to radiographic improvement beyond 12 months of follow-up.

A strength and a limitation of the study is that the same experienced paediatric radiologist undertook all of the reporting using standardised reporting methodology. ${ }^{12}$ The potential for interobserver variation in the interpretation of grade 0 (normal) and grade 1 (mild/moderate) radiographic abnormalities is well recognised. ${ }^{31}$ However, interobserver variation is less likely to impact on the reported incidence of more radiologically overt severe findings which, in our study, were mostly multifocal or diffusely distributed. Good interobserver agreement can be achieved by systematic and standardised reporting of such features, ${ }^{32}$ as in our study. A further limitation is the potential for underreporting of features such as bronchiectasis, which usually require CT for definitive diagnosis. Resource limitations and ethical concerns regarding unnecessary exposure to radiation precluded its use in most children. The prevalence of chronic radiological disease in this study may therefore be underestimated.

Although clinical features such as cough, respiratory rate and chest auscultation findings were recorded for all children at each follow-up visit, correlation with radiographic findings is difficult and could not be included in this analysis. However, there was a marked reduction in hospitalisation for acute LRTI over time, concomitant with clinical and radiological improvement.

Currently, an estimated 2.9 million children in SSA and 400000 in other resource-limited settings are HIV-infected. ${ }^{14}$ Our findings suggest that almost two million of these children may have persistent, severe chest radiographic abnormalities. Furthermore, in LMICs, only a third of those eligible are receiving ART, well short of the Millennium Development Goal of $100 \%$ ART coverage by $2015 .{ }^{33}$ The finding that ART can either reduce the risk of radiographic progression or reverse established abnormality underscores the importance of universal, early access to treatment.

Acknowledgements The authors thank the children and their caregivers for participating and the study staff for their work.

Contributors HJZ and MFC conceived the cohort study and supervised the cohort study staff at the respective sites. HJZ obtained funding for the cohort study, was responsible for overall oversight of the cohort study and overall supervision of the radiological aspects. LW was responsible for development of the database, database quality control and contributed to the analysis of the cohort study. CJL contributed to study design and statistical analysis of the cohort study and the statistical analysis of the radiological study. SJB cosupervised the radiological study. RDP was responsible for the study design, literature search, data collection, data analysis, data interpretation, figures, tables, manuscript writing and editing of the radiological study. All authors contributed to the final manuscript.

Funding Financial support for the study was provided by the Rockefeller Foundation, the South African Medical Research Council (MRC), National Research Foundation (NRF), the South African Department of Health (DoH) Research Program and the award of a University of Cape Town Harry Crossley Senior Clinical Research Fellowship to RDP.

Competing interests None declared.

Patient consent Parental/guardian consent obtained.

Ethics approval Research Ethics Committees of the Faculties of Health Sciences of the University of Cape Town and Stellenbosch University.

Provenance and peer review Not commissioned; externally peer reviewed.

Data sharing statement Three supplementary files are included. 


\section{REFERENCES}

1 Punpanich W, Groome M, Muhe L, et al. Systematic review on the etiology and antibiotic treatment of pneumonia in human immunodeficiency virus-infected children. Pediatr Infect Dis J 2011;30:e192-202.

2 Gray DM, Zar HJ. Community-acquired pneumonia in HIV-infected children: a global perspective. Curr Opin Pulm Med 2010;16:208-16.

3 Weber $\mathrm{HC}$, Gie RP, Cotton MF. The challenge of chronic lung disease in HIV-infected children and adolescents. JIAS 2013;16:18633.

4 Zar HJ. Chronic lung disease in human immunodeficiency virus (HIV) infected children. Pediatr Pulmonol 2008;43:1-10.

5 World Health Organization. Scaling up antiretroviral therapy in resource-limited settings: guidelines for a public health approach. Geneva: WHO, 2002. ISBN: 92-4154567-4

6 South African National Department of Health. HIV and AIDS Policy Guideline. National Antiretroviral Treatment Guidelines. 1st edn. Pretoria: Jacana, 2004. ISBN: 1-919931-69-4.

7 World Health Organization. Antiretroviral therapy of HIV infection in infants and children: towards universal access-recommendations for a public health approach. Geneva: WHO, Department of HIV/AIDS, 2006.

8 Prasitsuebsai W, Kariminia A, Puthanakit T, et al. Impact of Antiretroviral Therapy on Opportunistic Infections of HIV-Infected Children in the TREAT Asia Pediatric HIV Observational Database. Pediatr Infect Dis J 2014;33:747-52.

9 Micheloud D, Álvaro-Meca A, Jensen J, et al. Trend of pneumonia incidence among children infected with HIV in the era of highly active antiretroviral therapy. Pediatr Infect Dis J 2012;31:599-601.

10 Nunes MC, von Gottberg A, de Gouveia L, et al. The impact of antiretroviral treatment on the burden of invasive pneumococcal disease in South African children: a time series analysis. AIDS 2011;25:453-62.

11 Walters E, Cotton MF, Rabie H, et al. Clinical presentation and outcome of tuberculosis in human immunodeficiency virus infected children on anti-retroviral therapy. BMC Pediatr 2008;8:1.

12 Pitcher RD, Lombard C, Cotton MF, et al. Clinical and immunological correlates of chest X-ray abnormalities in HIV-infected South African children with limited access to anti-retroviral therapy. Pediatr Pulmonol 2014;49:581-8.

13 Norton KI, Kattan M, Rao JS, et al. P(2)C(2) HIV Study Group. Chronic radiographic lung changes in children with vertically transmitted HIV-1 infection. AJR Am J Roentgenol 2001;176:1553-8.

14 Joint United Nations Programme on HIVIAIDS (UNAIDS). Global report: UNAIDS report on the global AIDS epidemic 2013. ISBN: 978-92-9253-032-7.

15 Zar HJ, Cotton MF, Strauss S, et al. Effect of isoniazid prophylaxis on mortality and incidence of tuberculosis in children with HIV: randomised controlled trial. BMJ 2007;334:136.

16 Frigati LJ, Kranzer $\mathrm{K}$, Cotton MF, et al. The impact of isoniazid preventive therapy and antiretroviral therapy on tuberculosis in children infected with HIV in a high tuberculosis incidence setting. Thorax 2011;66:496-501.

17 Centers for Disease Control and Prevention. Revised classification system for human immunodeficiency virus infection in children less than 13 years of age. Morb Mortal Wkly Rep 1994;43:1-10.
18 Centers for Disease Control and Prevention. Classification system for human immunodeficiency virus (HIV) infection in children under 13 years of age. Morb Mortal Wkly Rep 1987;36:225-36.

19 Hesseling AC, Cotton MF, Jennings T, et al. High incidence of tuberculosis among HIV-infected infants: evidence from a South African population-based study highlights the need for improved tuberculosis control strategies. Clin Infect Dis 2009;48:108-14.

20 Marolda J, Pace B, Bonforte RJ, et al. Pulmonary manifestations of HIV-infection in children. Pediatr Pulmonol 1991;10:231-5.

21 Marquis JR, Berman CZ, DiCarlo F, et al. Radiographic patterns of PLH/LIP in HIV positive children. Pediatr Radiol 1993;23:328-30.

22 Sharland M, Gibb DM, Holland F. Respiratory morbidity from lymphocytic interstitial pneumonitis (LIP) in vertically acquired HIV infection. Arch Dis Child 1997;76:334-6

23 Lynch JL, Blickman JG, terMeulen DC, et al. Radiographic resolution of lymphocytic interstitial pneumonitis (LIP) in children with human immunodeficiency virus (HIV): not a sign of clinical deterioration. Pediatr Radiol 2001;31:299-303.

24 Bhoopat L, Rangkakulnuwat S, Okonogi R, et al. Cell reservoirs of the Epstein-Barr virus in biopsy-proven lymphocytic interstitial pneumonitis in HIV-1 subtype $E$ infected children: identification by combined in situ hybridization and immunohistochemistry. Appl Immunohistochem Mol Morphol 2010;18:212-18.

25 Bhoopat L, Rangkakulnuwat S, Ya-In C, et al. Relationship of cell bearing EBER and p24 antigens in biopsy-proven lymphocytic interstitial pneumonia in HIV-1 subtype $E$ infected children. Appl Immunohistochem Mol Morphol 2011;19:547-51.

26 Slyker JA, Casper C, Tapia K, et al. Clinical and virological manifestations of primary Epstein-Barr virus (EBV) infection in Kenyan infants born to HIV-infected women. JID 2013;207:1798-806.

27 Dufour $\mathrm{V}$, Wislez $\mathrm{M}$, Bergot $\mathrm{E}$, et al. Improvement of symptomatic human immunodeficiency virus-related lymphoid interstitial pneumonia in patients receiving highly active antiretroviral therapy. Clin Infect Dis 2003;36:e127-30.

28 Sturt AS, Halpern MS, Sullivan B, et al. Timing of antiretroviral therapy initiation and its impact on disease progression in perinatal human immunodeficiency virus-1 infection. Pediatr Infect Dis J 2012;31:53-60.

29 Barry O, Powell J, Renner $L$, et al. Effectiveness of first-line antiretroviral therapy and correlates of longitudinal changes in CD4 and viral load among HIV-infected children in Ghana. BMC Infect Dis 2013;13:476.

30 Hansudewechakul R, Sirisanthana V, Kurniati N, et al. TREAT Asia Pediatric HIV Observational Database. Antiretroviral therapy outcomes of HIV-infected Children in the TREAT Asia pediatric HIV observational database. J Acquir Immune Defic Syndr 2010;55:503-9.

31 Cleveland RH, Schluchter M, Wood BP, et al. Chest radiographic data acquisition and quality assurance in multicentre studies. Pediatr Radiol 1997;27:880-7.

32 Cherian T, Mulholland EK, Carlin JB, et al. Standardized interpretation of paediatric chest radiographs for the diagnosis of pneumonia in epidemiological studies. Bull World Health Organ 2005;83:353-9.

33 United Nations Department of Economic and Social Affairs, Statistics Division. Millennium Development Goals Indicators. http://mdgs.un.org/unsd/mdg/host.aspx? Content=indicators/officiallist.htm (accessed 30 Oct 2014). 